OPEN ACCESS

Edited by:

Ulrike Koehl,

Hannover Medical School, Germany

Reviewed by:

Karl-Johan Malmberg,

Oslo University Hospital, Norway

Adelheid Cerwenka,

German Cancer Research Center,

Germany

*Correspondence:

Ofer Mandelboim

oferm@ekmd.huji.ac.il

Specialty section:

This article was submitted to Alloimmunity and Transplantation,

a section of the journal

Frontiers in Immunology

Received: 24 October 2016 Accepted: 20 March 2017

Published: 11 April 2017

Citation:

Schmiedel D and Mandelboim O (2017) Disarming Cellular Alarm

Systems-Manipulation of Stress-Induced NKG2D Ligands by Human Herpesviruses.

Front. Immunol. 8:390. doi: 10.3389/fimmu.2017.00390

\section{Disarming Cellular Alarm Systems - Manipulation of Stress-Induced NKG2D Ligands by Human Herpesviruses}

\section{Dominik Schmiedel and Ofer Mandelboim*}

Faculty of Medicine, The Lautenberg Center for General and Tumor Immunology, The BioMedical Research Institute Israel-Canada, The Hebrew University Hadassah Medical School, Jerusalem, Israel

The coevolution of viruses and their hosts led to the repeated emergence of cellular alert signals and viral strategies to counteract them. The herpesvirus family of viruses displays the most sophisticated repertoire of immune escape mechanisms enabling infected cells to evade immune recognition and thereby maintain infection. The herpesvirus family consists of nine viruses that are capable of infecting humans: herpes simplex virus 1 and 2 (HSV-1, HSV-2), varicella zoster virus (VZV), Epstein-Barr virus (EBV), human cytomegalovirus (HCMV), roseoloviruses (HHV-6A, HHV-6B, and HHV-7), and Kaposi'ssarcoma-associated herpesvirus (KSHV). Most of these viruses are highly prevalent and infect a vast majority of the human population worldwide. Notably, research over the past 15 years has revealed that cellular ligands for the activating receptor natural-killer group 2, member D (NKG2D) - which is primarily expressed on natural killer (NK) cells are common targets suppressed during viral infection, i.e., their surface expression is reduced in virtually all lytic herpesvirus infections by diverse mechanisms. Here, we review the viral mechanisms by which all herpesviruses known to date to downmodulate the expression of the NKG2D ligands. Also, in light of recent findings, we speculate about the importance of the emergence of eight different NKG2D ligands in humans and further allelic diversification during host and virus coevolution.

Keywords: NKG2D ligands, stress-induced ligands, NKG2D, herpesvirus, host-pathogen interaction, immune evasion, coevolution

\section{HERPESVIRUSES - CONSTANT COMPANIONS DURING HUMAN LIFE AND EVOLUTION}

Herpesviruses have accompanied humankind since the dawn of evolution. Herpesvirus infections date back at least 6 million years, even before evolutionary split between hominids and chimpanzees (1). From that time on, viral strategies to ensure survival and dissemination coevolved together with the immune system that continuously developed new measures to clear viral infections.

To date, nine different herpesviruses capable of infecting humans have been identified: HSV-1, HSV-2, varicella zoster virus (VZV), Epstein-Barr virus (EBV), human cytomegalovirus (HCMV), HHV-6A, HHV-6B, HHV-7, and Kaposi's-sarcoma-associated herpesvirus (KSHV) (2).

Despite their different life cycle and growth properties, cellular tropisms and although they cause different diseases, all herpesviruses share common features. They are enveloped and contain a linear, double-stranded DNA genome, ranging from $125 \mathrm{~kb}$ (for VZV) to $235 \mathrm{~kb}$ (for HCMV) (2). 
Furthermore, all have the ability not only to infect lytically but also to establish life-long infection in their host, a status called latency, which is a dormant infection lacking pathology and viral replication $(2,3)$.

Most herpesviruses are widely spread in human populations. Serological tests reveal that HSV-1, VZV, EBV, HHV-6, and HHV-7 have the highest prevalence of the herpesvirus family and infect about $90 \%$ of the adult population (4-10). Notably, the prevalence of herpesviruses varies geographically and is influenced by socioeconomic status $(2,11,12)$. HCMV prevalence can therefore vary between 50 and 100\% dependent on the population studied (13). Some herpesviruses reactivate symptomatically and frequently in healthy individuals for as yet unknown reasons, while others only cause symptomatic reactivation in immunodeficient patients (3). However, research over the past few years revealed that all herpesviruses use common strategies during primary infection, reactivation, and sometimes even during latency, in order to evade the immune surveillance during the different phases of herpesvirus life cycle. The interactions between adaptive immunity and herpesviruses are described elsewhere (14-17). In this review, we will focus on the interaction of herpesviruses and natural-killer group 2, member D (NKG2D)-expressing immune cells. The humanactivating receptor NKG2D is expressed on all natural killer (NK) cells as well as on most T cells including $\gamma \delta$ T cells and NK $\mathrm{T}$ cells (18). Its importance was shown for tumor surveillance (19) and inflammatory diseases (20). The significance of NK cells in herpesvirus immune surveillance becomes clear by looking at NK cell-deficient individuals who suffer from recurrent, severe, potentially life-threatening herpesvirus infections $(21,22)$.

\section{GENETICS OF NKG2D LIGANDS}

In the course of human evolution, eight different, functional ligands for the NKG2D receptor emerged: MHC class I polypeptide-related sequence A and B (MICA and MICB, respectively) and the unique long 16 binding protein 1-6 (ULBP1-6) (23). Also known as "stress-induced ligands," they are barely found on healthy cells in order to avoid auto-reactivity toward normal tissues. These ligands, however, are upregulated and expressed on the cell surface following various stresses including genotoxic stress, oncogene activation or hypoxia that are commonly seen in tumorigenesis, or following viral infection $(24,25)$.

All NKG2D ligands belong to the MHC class I-like protein family. ULBP family members have an $\alpha 1 / \alpha 2$ domain structure, whereas the MIC proteins possess an $\alpha 1 / \alpha 2 / \alpha 3$ domain structure (26). Interestingly, classical MHC class I proteins serve mainly as inhibitory ligands for NK cells, whereas the NKG2D ligands activate NK cells $(27,28)$.

Up until now, 16 different allelic variants were identified for the 6 members of the ULBP family (29). More than 100 different MICA alleles and more than 40 MICB alleles were identified to date; a finding that demonstrates the striking superior evolutionary plasticity of the MIC family [http://hla.alleles.org/alleles/classo. html; (30)] (Figure 1). The reason behind this enormous diversity of the MIC family is still unknown. MIC genes lack hypervariable regions; point mutations and genetic shuffles occur over all three domains (31). Comparing amino acid sequence homology, MICA and MICB are very similar (about $85 \%$ identity), whereas the similarity to ULBP family proteins is comparatively low (only about $20-25 \%$ identity between MIC and ULBP proteins). ULBP family members shares about $60 \%$ amino acid sequence identity with each other (32-34). Interestingly, MICA, MICB, ULBP4, and ULBP5 contain a transmembrane domain and a cytoplasmic tail, whereas ULBP1, ULBP2, ULBP3, ULBP6, and one particular allelic variant of MICA (allele ${ }^{\star} 008$ ) are glycosylphosphatidylinositol (GPI) anchored (30).

Only recently, post-transcriptional cellular mechanisms that control stress-induced ligand expression by RNA-binding proteins $(35-37)$ and microRNAs (miRNAs) $(38,39)$ began to be unraveled; however, the regulatory circuits and expression patterns in normal cells remain incompletely understood. By contrast, much information was gathered about the suppression of NKG2D ligands during herpesvirus infection, emphasizing the importance of the receptor NKG2D for anti-viral immunity.

\section{ALL HERPESVIRUSES SUPPRESS EXPRESSION OF STRESS-INDUCED LIGANDS DURING INFECTION}

\section{HSV-1 and -2-HHV-1 and -2}

Herpes simplex virus 1 and 2 can cause orofacial and genital infections in elsewise healthy individuals with a competent immune system (40). Reactivation is believed to be triggered by stress, sunlight, fever, or skin traumas, e.g., caused by surgery $(40,41)$.

The effects of HSV-1 infection on the expression of NKG2D ligands were first studied by Schepis et al. [(42); Figure 1; Table 1]. Both ULBP2 and MICA surface expression levels were found to be decreased following infection with HSV-1 strain F. Concurrent with a loss of surface expression, MICA messenger RNA (mRNA) levels were decreased. Since MICA downregulation was abrogated by inhibiting the viral DNA polymerase, the authors concluded that a late viral gene is responsible for the reduction of MICA expression. However, in this study, none of the cell lines tested expressed other ligands besides MICA and ULBP2. Another study, performed by Campbell et al., confirmed the decrease in MICA and ULBP2, but could additionally show a downregulation of ULBP1 and ULBP3 (43). Interestingly, MICA, ULBP2, and ULBP3 were shown to be reduced at the overall protein level, whereas ULBP1 was retained intracellularly, proving that different mechanisms act on these ligands (43).

In a subsequent study, Enk et al. added some mechanistic detail about the regulation of ULBP2 and ULBP3 (44). They reported that the viral miRNA miR-H8 interferes with the generation of GPI-anchored proteins by targeting PIGT, a key protein in the GPI-anchoring process $(45,46)$. Consequently, both ULBP2 and ULBP3 levels were reduced in miR-H8 overexpressing cells. Interestingly, ULBP1 is also GPI anchored but not affected by this pathway, explaining the necessity for another mechanism of downregulation-intracellular retention. However, since both MICA (except the allele $\mathrm{MICA}^{\star} 008$ ) and MICB are transmembrane proteins and were not affected by the miR-H8 overexpression, 


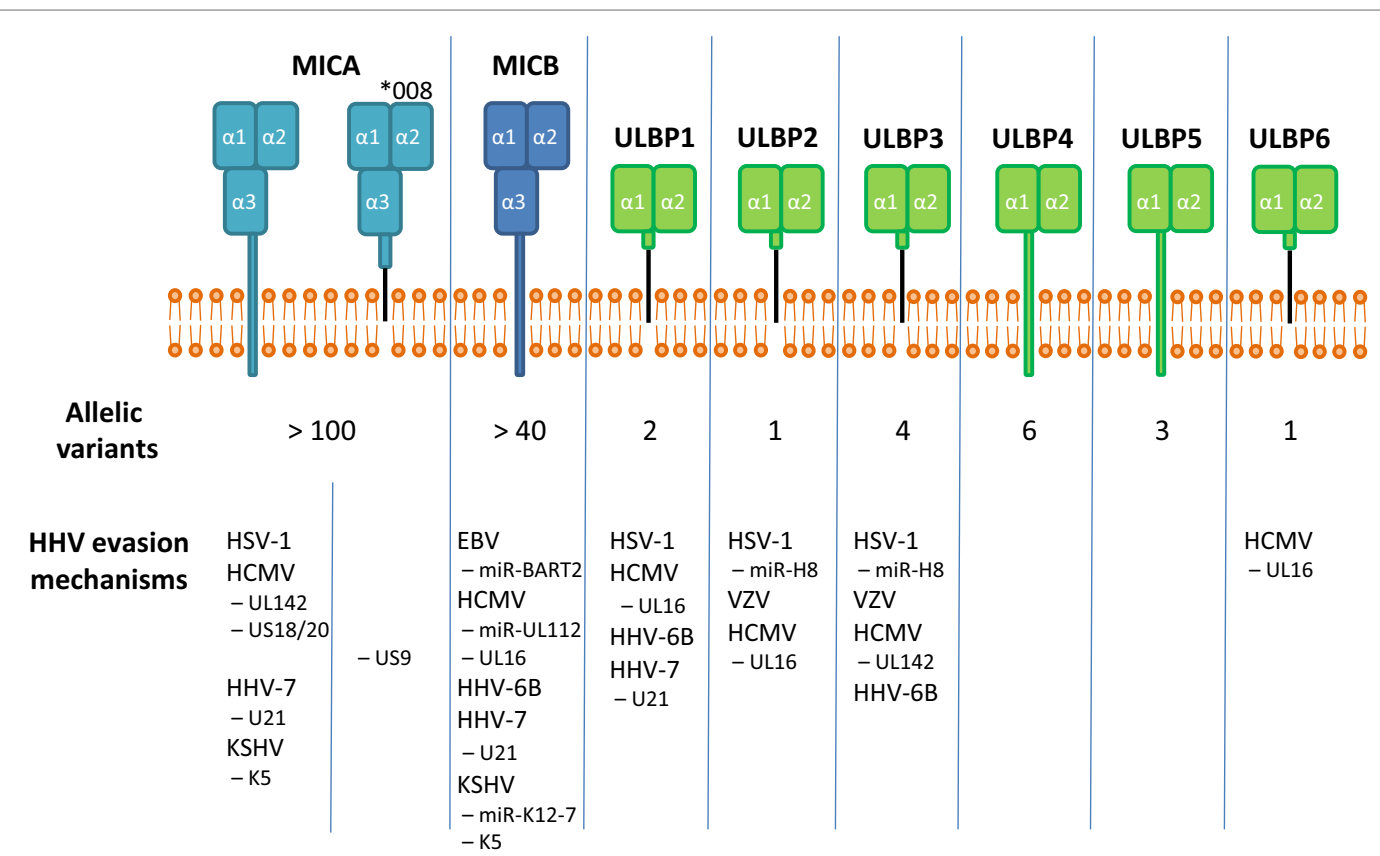

FIGURE 1 | The human genome encodes for eight functional stress-induced ligands, subdivided in the MIC and ULBP family. MICA, MICB, ULBP4, and ULBP5 contain a transmembrane domain, whereas ULBP1, 2, and 3 and one particular allele of MICA, MICA*008, are GPI-anchored. Interestingly, MICA and MICB, genes having a high evolutionary plasticity as reflected by the number of allelic variants, seem to be targeted more frequently by viral immune evasion mechanisms.

the viral mechanism responsible for these downregulations are still unknown.

\section{VZV-HHV-3}

Varicella zoster virus is the causative agent of varicella (chickenpox) in primary infection (47). In the elderly or immunosuppressed patients, VZV can reactivate and cause herpes zoster (shingles), which is characterized by painful skin lesions as well as neurological and ocular disorders $(47,48)$.

By infecting retinal epithelial cells with a clinical VZV strain, Campbell et al. revealed a down-modulation of the surface expression of the NKG2D ligands ULBP2 and ULBP3 [(43); Figure 1; Table 1]. By contrast, MICA surface expression increased during the course of VZV infection; ULBP1 and MICB were not expressed in the studied cells. Due to the overall reduction of surface expression of NKG2D ligands, reduced activation of NK cells in the presence of VZV-infected cells as compared to mock infected cells was observed. Interestingly, the total protein levels of ULBP2 and ULBP3 were not reduced in infected cells (43), indicating intracellular retention of these ligands by a yet unknown viral factor.

\section{EBV-HHV-4}

Epstein-Barr virus is usually acquired asymptomatically in childhood $(2,49)$. Infection during adolescence can lead to infectious mononucleosis (in about $50 \%$ of primary infections), a weakening and sometimes painful but self-limiting disease associated with the occurrence of atypical lymphocytes in the blood stream (2, 49). Reactivation can occur in immunocompromised individuals and is, among others, linked not only to lympho-proliferative diseases such as Burkitt's and Hodgkin's lymphoma but also to nasopharyngeal carcinoma $(50,51)$.

A sensitization of EBV-infected cells switching from latent to lytic infection to NK cell killing was reported by Pappworth et al. (52). They showed the induction of ULBP1 following this switch in a Burkitt's lymphoma-derived cell line, whereas all other NKG2D ligands were absent from the cell surface. Later on, an overexpression study performed by Nachmani et al. revealed that the latency-associated viral miRNA miR-BART2-5p is capable of binding MICB mRNA and suppressing its translation [(53); Figure 1; Table 1]. Interestingly, they showed that the binding site in the MICA mRNA sequence was mutated in such a way that prevented the miRNA from suppressing MICA as well.

Remarkably, to the best of our knowledge, there are no immune evasion mechanisms regarding NKG2D ligands during lytic EBV infection described to date. This phenomenon might be explained by a study published by Song et al. (54). They showed that EBVtransformed B cells produce and release the tryptophan-derived metabolite L-kynurenine that downmodulates NKG2D receptor expression on by-stander NK cells. Therefore, the suppression of NKG2D ligands on infected cells might be of little importance if the effector cells themselves are effectively disarmed.

\section{HCMV-HHV-5}

While being a harmless pathogen for immunocompetent individuals, HCMV constitutes a major risk for the elderly, patients after organ transplantation and AIDS patients (55). Additionally, primary infection in pregnant women can cause miscarriage, stillbirth, or developmental retardation of the child (55). HCMV possesses the largest genome of all HHVs of about $235 \mathrm{~kb}$ (2). 
TABLE 1 | Overview of known suppression mechanisms for NKG2D ligands by HHVs.

\begin{tabular}{|c|c|c|c|c|}
\hline & Viral effector & Ligand & Mechanism & Reference \\
\hline \multirow[t]{4}{*}{ HSV-1 } & $?$ & MICA & $?$ & $(42,43)$ \\
\hline & $?$ & ULBP1 & Intracellular retention & $(43)$ \\
\hline & $\mathrm{miR}-\mathrm{H} 8$ & ULBP2 & Interferes with protein maturation & $(42-44)$ \\
\hline & $\mathrm{miR}-\mathrm{H} 8$ & ULBP3 & Interferes with protein maturation & $(43,44)$ \\
\hline HSV-2 & $?$ & $?$ & $?$ & $?$ \\
\hline \multirow[t]{2}{*}{ Varicella zoster virus } & $?$ & ULBP2 & Intracellular retention & (43) \\
\hline & $?$ & ULBP3 & Intracellular retention & \\
\hline Epstein-Barr virus & miR-BART2-5p & MICB & Translational repression & (53) \\
\hline \multirow[t]{9}{*}{ Human cytomegalovirus } & miR-UL112 & MICB & Translation repression & (56) \\
\hline & UL16 & MICB & Intracellular retention & (60) \\
\hline & & ULBP1 & Intracellular retention & $(32,57)$ \\
\hline & & ULBP2 & Intracellular retention & $(32,57)$ \\
\hline & & ULBP6 & Intracellular retention & $(61)$ \\
\hline & UL142 & MICA & Intracellular retention & (62) \\
\hline & & ULBP3 & Intracellular retention & (63) \\
\hline & US18/US20 & MICA & Lysosomal degradation & (64) \\
\hline & US9 & $\mathrm{MICA}{ }^{\star} 008$ & Proteasomal degradation & (68) \\
\hline $\mathrm{HHV}-6 \mathrm{~A}$ & $?$ & $?$ & $?$ & $?$ \\
\hline \multirow[t]{3}{*}{ HHV-6B } & $?$ & MICB & Proteasomal degradation & $(71)$ \\
\hline & $?$ & ULBP1 & Proteasomal degradation & \\
\hline & $?$ & ULBP3 & Proteasomal degradation & \\
\hline \multirow[t]{3}{*}{$\mathrm{HHV}-7$} & U21 & MICA & $?$ & $(72)$ \\
\hline & & MICB & $?$ & \\
\hline & & ULBP1 & Lysosomal degradation & \\
\hline \multirow[t]{3}{*}{ Kaposi's-sarcoma-associated herpesvirus } & K5 & MICA & Ubiquitinylation/intracellular retention & $(75)$ \\
\hline & & MICB & Ubiquitinylation/intracellular retention & (75) \\
\hline & miR-K12-7 & MICB & Translational repression & (53) \\
\hline
\end{tabular}

?, no published data available.

Therefore, it might not be surprising that HCMV has the greatest number of viral mechanisms dedicated to the immune evasion by manipulating NKG2D ligands described to date.

The first viral miRNA identified to target immune molecules in general and NKG2D ligands in particular was miR-UL112, discovered by Stern-Ginossar et al. [(56); Figure 1; Table 1]. By binding to the $3^{\prime}$-UTR of the MICB mRNA, it represses translation, and surface levels are rapidly reduced, leading to decreased NK cell activation. UL16 was the first HCMV viral protein found to bind and retain ULBP1, ULBP2, ULBP6, and MICB intracellularly ("ULBPs" were named for being UL16-binding proteins) (32, 57-61). Later, UL142 was shown to sequester both MICA and ULBP3 intracellularly, they colocalized with markers of the cis-Golgi apparatus inside infected cells $(62,63)$.

Fielding et al. showed that the viral proteins US18 and US20 are capable of both independently and synergistically downregulating MICA expression by targeting it for lysosomal degradation (64).

Notably, the GPI-anchored allele MICA*008 was not found to be targeted by the abovementioned viral mechanisms and was therefore considered as HCMV-resistant escape variant. Since the $\mathrm{MICA}^{\star} 008$ allele is a highly prevalent in human populations worldwide, the hypothesis was formed that its prevalence is the result of viral selective pressure (65-67). However, Seidel et al. showed that this supposed escape variant is specifically targeted by the HCMV protein US9 during its maturation process, prior to its egress from the ER, instead forcing $\mathrm{MICA}^{\star} 008$ to proteasomal degradation (68).

\section{Roseoloviruses-HHV-6A, HHV-6B, and HHV-7}

HHV-6A, $-6 \mathrm{~B}$, and -7 have long been neglected in research. Only in the past years have these viruses gained attention since it became obvious that they not only cause a common children's disease (roseola infantum) but might also be involved in severe illnesses, especially in immunoincompetent individuals like neuroinflammatory diseases (HHV-6A), transplant rejection, myocarditis (HHV-6B), or encephalitis (HHV-6A, $-6 \mathrm{~B}$, and HHV-7) $(69,70)$. For this reason, immunomodulatory features of these viruses were studied only relatively recently.

We showed that HHV-6B strain Z29 is capable of suppressing the surface expression of the NKG2D ligands ULBP1, ULBP3, and MICB, but not MICA or ULBP2 [(71); Figure 1; Table 1]. This was true both in primary $\mathrm{T}$ cells and in $\mathrm{T}$ cell lines. As a cellular response to the viral infection, mRNA levels of all stress-induced ligands rise following infection; however, the virus suppresses the three abovementioned ligands on protein level and degrades them rapidly in a proteasome-dependent pathway shortly after the start of infection. Also, we showed that the degradation of the three ligands is mediated by at least two different viral proteins.

As for HHV-7, Schneider et al. showed that U21, which was previously shown to target HLA class I for lysosomal degradation, also causes lysosomal degradation of ULBP1 resulting in a mild downregulation. Additionally, they observed a major downregulation of MICA and MICB (72). These findings were 
established using the overexpression of the viral protein U21. However, the exact mechanism for MIC proteins degradation remained unclear. Probably, U21 interferes with proper protein glycosylation rendering the MIC proteins unstable and causing them to be targeted for cellular degradation. Due to the mild loss of ULBP1, this degradation was proposed to be the result of a "side-effect" of U21-mediated HLA class I degradation, since these related proteins were targeted to lysosomal degradation with higher affinity and to a greater extent.

However, since the study was limited to overexpression of a single gene and no studies were conducted using an actual infection model, it is possible that additional stress-induced ligands are affected by HHV-7 or that additional mechanisms targeting the same ligands exist.

\section{KSHV-HHV-8}

Kaposi's-sarcoma-associated herpesvirus is the human herpesvirus with the lowest seroprevalence in the Western world with only about $1-3 \%$ of individuals infected (73). Still, this virus is a significant cause of cancer, primarily in AIDS patients, whereas immunocompetent individuals do not experience KSHV reactivation $(73,74)$. In developing countries, seroprevalence is substantially higher (73).

During lytic infection, KSHV evades NK cell recognition by expressing the viral E3 ligase K5. Thomas et al. showed that $\mathrm{K} 5$ modifies lysine residues within the cytoplasmic tails of both MICA and MICB with ubiquitin. Consequently, these molecules are internalized from the cell membrane and intracellularly sequestered, but not degraded [(75); Figure 1; Table 1]. Notably, the fact that the MICA allele ${ }^{\star} 008$ as well as ULBP1, ULBP2, and ULBP3 are GPI anchored and therefore lack a cytoplasmic tail, render them resistant to K5-mediated ubiquitinylation. Additionally, Nachmani et al. reported that the viral miRNA miRK12-7 specifically represses the translation of MICB by binding to the $3^{\prime}$-UTR of its mRNA (53). Interestingly, MICA mRNA was shown not to be targeted by miR-K12-7 since the $3^{\prime}$-UTR is significantly shorter than the MICB equivalent and does not contain the binding site (53).

\section{EIGHT LIGANDS, FURTHER ALLELIC DIVERSIFICATION: HOST-PATHOGEN EVOLUTION AT FULL SPEED}

As emphasized above, herpesvirus family members developed numerous mechanisms to interfere with the expression of the stress-induced ligands. However, most of these studies still leave unanswered questions. More mechanisms and viral effectors are still waiting to be discovered. The viral protein repertoire is probably much larger than currently known; by using ribosome profiling of HCMV and KSHV, numerous new open reading frames (ORFs) have been identified $(76,77)$. The functions of many viral proteins and ORFs are yet unknown and we are just on the verge of understanding the importance of viral non-coding RNAs, including long non-coding RNAs $(78,79)$.
While the NKG2D receptor itself is conserved among species, its ligands are not. Interestingly, having eight functional ligands of two different families (MIC and ULBP) and various alleles, the human NKG2D ligand repertoire is more complex than that of other species. Mice possess even nine functional ligands (MULT1, Raet1 $\alpha-\varepsilon$, H60a-c) (80). However, their domain structure reveals them to be ULBP family homologs with low allelic diversity. Non-human primates were shown to have homologs of the MIC proteins $(81,82)$. Still, compared to humans with more than 100 allelic variants, even great apes seem to possess lower allelic variation (83).

Herpesviruses might be a major driving force for diversification of stress-induced ligands and further mutagenesis within alleles leading to allelic variations. None of the described viral mechanisms is capable of eliminating the expression of all stress-induced ligands, the evolutionary pressure rendered these ligands so diverse that no single viral protein or RNA is sufficient to regulate all of them.

As described earlier, viral miRNAs of HCMV, EBV, and KSHV target MICB mRNA at different sites of its $3^{\prime}$-UTR and suppress protein translation $(53,56)$. Despite the high degree of sequence homology in their $3^{\prime}$-UTRs, MICA is not targeted by any of these miRNAs. The binding sites for the viral miRNAs of HCMV (miR-UL112) and EBV (miR-BART2-5p) are modified by a single-nucleotide insertion, thus abolishing miRNA-induced translation repression. The sequence that is targeted by the KSHV encoded miR-K12-7 is completely absent due to a major deletion in the MICA $3^{\prime}$-UTR.

A similar mutagenesis apparently occurred in the MICA protein to escape UL16 binding. UL16 binds to an $\alpha$-helical structure in the $\alpha 2$ domain of MICB. By substituting single amino acid residues in MICB with their MICA equivalents, Spreu et al. could show that a single substitution (at two different positions) is sufficient to abolish UL16 binding (84); hence, MICA is spared from UL16-mediated intracellular retention by virtue of very few mutations. Additionally, Klumkrathok et al. suggested that even different allelic variants of MICB are bound with different affinities by UL16 due to amino acid substitutions in the $\alpha 2$ domain (85).

A third piece of evidence for a herpesvirus-driven coevolution is the emergence of $\mathrm{MICA}^{\star} 008$, a highly prevalent, GPI-anchored MICA variant. $\mathrm{MICA}^{\star} 008$ is not targeted by UL142, by US18, or by US20. Only recently, it was discovered that the evolutionary relatively novel US9 is capable of targeting solely this distinct allele, but none of the full-length alleles containing a transmembrane domain (68).

These few examples illustrate well the human capability to adjust to viral immune evasion strategies. Accordingly, this strong selective, coevolutionary pressure necessitates modification of viral effector molecules targeting the immune surveillance system as well. By comparing different isolates from HCMV-infected individuals, Renzette et al. and Sijmons et al. indeed showed on a global level that genes involved in immune evasion within the HCMV genome are strongly diversified and contain high numbers of single-nucleotide polymorphisms $(86,87)$. Among others, one particular mutable gene was found to be UL142, which interacts with NKG2D ligands as pointed out before (87). 


\section{DIVERSIFICATION: AN EVOLUTIONARY NECESSITY?}

It seems obvious to conclude that herpesviruses and ligands for NKG2D continuously shape each other during coevolution, whereas the NKG2D receptor itself remains conserved.

Particularly MICA took the lead in this race on the human side, its $3^{\prime}$-UTR became shortened and modified and numerous allelic variations emerged to withstand herpesvirus infection. The diversity of MICA alleles might thereby even create a "population level resistance" by making it difficult for newly emerging viral mechanisms to successfully target all MICA variants at once.

However, in contradiction to this theory and the supposed importance of stress-ligand evolution, several reports showed a wide distribution of a MICA-MICB null haplotype (also described as MICA-del-MICB-null), a phenotype that occurs mainly, but not exclusively, in East Asia (88-91), apparently with no major evolutionary disadvantage or clinical manifestations.

\section{REFERENCES}

1. Wertheim JO, Smith MD, Smith DM, Scheffler K, Kosakovsky Pond SL. Evolutionary origins of human herpes simplex viruses 1 and 2. Mol Biol Evol (2014) 31:2356-64. doi:10.1093/molbev/msul85

2. Arvin A, Campadelli-Fiume G, Mocarski E, Moore PS, Roizman B, Whitley $\mathrm{R}$, et al. Human Herpesviruses: Biology, Therapy, and Immunoprophylaxis. Cambridge: Cambridge University Press (2007).

3. Grinde B. Herpesviruses: latency and reactivation - viral strategies and host response. J Oral Microbiol (2013) 5. doi:10.3402/jom.v5i0.22766

4. Cohen JI. Epstein-Barr virus infection. N Engl J Med (2000) 343:481-92. doi:10.1056/NEJM200008173430707

5. Kowitdamrong E, Pancharoen C, Thammaborvorn R, Bhattarakosol P. The prevalence of varicella-zoster virus infection in normal healthy individuals aged above 6 months. J Med Assoc Thai (2005) 88(Suppl 4):S7-11.

6. Wald A, Corey L. Persistence in the population: epidemiology, transmission. In: Arvin A, Campadelli-Fiume G, Mocarski E, Moore PS, Roizman B, Whitley R, et al., editors. Human Herpesviruses: Biology, Therapy, and Immunoprophylaxis. Cambridge: Cambridge University Press (2007).

7. Hjalgrim H, Friborg J, Melbye M. The epidemiology of EBV and its association with malignant disease. In: Arvin A, Campadelli-Fiume G, Mocarski E, Moore PS, Roizman B, Whitley R, et al., editors. Human Herpesviruses: Biology, Therapy, and Immunoprophylaxis. Cambridge: Cambridge University Press (2007).

8. Emery VC, Clark DA. HHV-6A, 6B, and 7: persistence in the population, epidemiology and transmission. In: Arvin A, Campadelli-Fiume G, Mocarski E, Moore PS, Roizman B, Whitley R, et al., editors. Human Herpesviruses: Biology, Therapy, and Immunoprophylaxis. Cambridge: Cambridge University Press (2007).

9. Lee BW. Review of varicella zoster seroepidemiology in India and Southeast Asia. Trop Med Int Health (1998) 3:886-90. doi:10.1046/j.1365-3156.1998. 00316.x

10. Wutzler P, Farber I, Wagenpfeil S, Bisanz H, Tischer A. Seroprevalence of varicella-zoster virus in the German population. Vaccine (2001) 20:121-4. doi:10.1016/S0264-410X(01)00276-6

11. Hofscheier A, Ponciano A, Bonzheim I, Adam P, Lome-Maldonado C, Vela T, et al. Geographic variation in the prevalence of Epstein-Barr viruspositive diffuse large B-cell lymphoma of the elderly: a comparative analysis of a Mexican and a German population. Mod Pathol (2011) 24:1046-54. doi:10.1038/modpathol.2011.62

12. Balfour HH Jr, Sifakis F, Sliman JA, Knight JA, Schmeling DO, Thomas W. Age-specific prevalence of Epstein-Barr virus infection among individuals aged 6-19 years in the United States and factors affecting its acquisition. J Infect Dis (2013) 208:1286-93. doi:10.1093/infdis/jit321
In fact, there are several known MICA-null alleles also independent of this haplotype. If and how MICA and MICB functions are compensated in these individuals, e.g., by the redundancy of the other NKG2D ligands that are still present, has yet to be elucidated; however, this phenomenon teaches us that we are still far from a complete understanding of the complex families of NKG2D ligands.

\section{AUTHOR CONTRIBUTIONS}

DS outlined, wrote, referenced the manuscript, and prepared the figure and table. OM supervised and carefully edited the work.

\section{FUNDING}

The study was funded by the European Research Council (ERC) grant-320473-BacNK-(to OM) and by the Seventh Framework Programme FP7-PEOPLE-2012-ITN-317013 (to DS and $\mathrm{OM})$.

13. Manicklal S, Emery VC, Lazzarotto T, Boppana SB, Gupta RK. The "silent" global burden of congenital cytomegalovirus. Clin Microbiol Rev (2013) 26:86-102. doi:10.1128/CMR.00062-12

14. Loewendorf A, Benedict CA. Modulation of host innate and adaptive immune defenses by cytomegalovirus: timing is everything. J Intern Med (2010) 267:483-501. doi:10.1111/j.1365-2796.2010.02220.x

15. Kinchington PR, Leger AJ, Guedon JM, Hendricks RL. Herpes simplex virus and varicella zoster virus, the house guests who never leave. Herpesviridae (2012) 3:5. doi:10.1186/2042-4280-3-5

16. $\mathrm{Hu} \mathrm{Z}$, Usherwood EJ. Immune escape of gamma-herpesviruses from adaptive immunity. Rev Med Virol (2014) 24:365-78. doi:10.1002/rmv.1791

17. Wang FZ, Pellett PE. HHV-6A, 6B, and 7: immunobiology and host response. In: Arvin A, Campadelli-Fiume G, Mocarski E, Moore PS, Roizman B, Whitley R, et al., editors. Human Herpesviruses: Biology, Therapy, and Immunoprophylaxis. Cambridge: Cambridge University Press (2007).

18. Ullrich E, Koch J, Cerwenka A, Steinle A. New prospects on the NKG2D/ NKG2DL system for oncology. Oncoimmunology (2013) 2:e26097. doi:10.4161/onci.26097

19. Guerra N, Tan YX, Joncker NT, Choy A, Gallardo F, Xiong N, et al. NKG2Ddeficient mice are defective in tumor surveillance in models of spontaneous malignancy. Immunity (2008) 28:571-80. doi:10.1016/j.immuni.2008.02.016

20. Guerra N, Pestal K, Juarez T, Beck J, Tkach K, Wang L, et al. A selective role of NKG2D in inflammatory and autoimmune diseases. Clin Immunol (2013) 149:432-9. doi:10.1016/j.clim.2013.09.003

21. Orange JS. Human natural killer cell deficiencies and susceptibility to infection. Microbes Infect (2002) 4:1545-58. doi:10.1016/S1286-4579(02)00038-2

22. Orange JS. Natural killer cell deficiency. J Allergy Clin Immunol (2013) 132:515-525; quiz 526. doi:10.1016/j.jaci.2013.07.020

23. Raulet DH. Roles of the NKG2D immunoreceptor and its ligands. Nat Rev Immunol (2003) 3:781-90. doi:10.1038/nri1199

24. Nausch N, Cerwenka A. NKG2D ligands in tumor immunity. Oncogene (2008) 27:5944-58. doi:10.1038/onc.2008.272

25. Gonzalez S, Lopez-Soto A, Suarez-Alvarez B, Lopez-Vazquez A, Lopez-Larrea C. NKG2D ligands: key targets of the immune response. Trends Immunol (2008) 29:397-403. doi:10.1016/j.it.2008.04.007

26. Groh V, Bahram S, Bauer S, Herman A, Beauchamp M, Spies T. Cell stressregulated human major histocompatibility complex class I gene expressed in gastrointestinal epithelium. Proc Natl Acad Sci U S A (1996) 93:12445-50. doi:10.1073/pnas.93.22.12445

27. Lanier LL. NK cell receptors. Annu Rev Immunol (1998) 16:359-93 doi:10.1146/annurev.immunol.16.1.359

28. Anfossi N, Andre P, Guia S, Falk CS, Roetynck S, Stewart CA, et al. Human NK cell education by inhibitory receptors for MHC class I. Immunity (2006) 25:331-42. doi:10.1016/j.immuni.2006.06.013 
29. Eagle RA, Trowsdale J. Promiscuity and the single receptor: NKG2D. Nat Rev Immunol (2007) 7:737-44. doi:10.1038/nri2144

30. Fernandez-Messina L, Reyburn HT, Vales-Gomez M. Human NKG2Dligands: cell biology strategies to ensure immune recognition. Front Immunol (2012) 3:299. doi:10.3389/fimmu.2012.00299

31. Choy MK, Phipps ME. MICA polymorphism: biology and importance in immunity and disease. Trends Mol Med (2010) 16:97-106. doi:10.1016/ j.molmed.2010.01.002

32. Cosman D, Mullberg J, Sutherland CL, Chin W, Armitage R, Fanslow W, et al. ULBPs, novel MHC class I-related molecules, bind to CMV glycoprotein UL16 and stimulate NK cytotoxicity through the NKG2D receptor. Immunity (2001) 14:123-33. doi:10.1016/S1074-7613(01)00095-4

33. Li P, Morris DL, Willcox BE, Steinle A, Spies T, Strong RK. Complex structure of the activating immunoreceptor NKG2D and its MHC class I-like ligand MICA. Nat Immunol (2001) 2:443-51. doi:10.1038/87757

34. Holmes MA, Li P, Petersdorf EW, Strong RK. Structural studies of allelic diversity of the MHC class I homolog MIC-B, a stress-inducible ligand for the activating immunoreceptor NKG2D. J Immunol (2002) 169:1395-400. doi:10.4049/jimmunol.169.3.1395

35. Nachmani D, Gutschner T, Reches A, Diederichs S, Mandelboim O. RNAbinding proteins regulate the expression of the immune activating ligand MICB. Nat Commun (2014) 5:4186. doi:10.1038/ncomms5186

36. Gowen BG, Chim B, Marceau CD, Greene TT, Burr P, Gonzalez JR, et al. A forward genetic screen reveals novel independent regulators of ULBP1, an activating ligand for natural killer cells. Elife (2015) 4:e08474. doi:10.7554/ eLife. 08474

37. Schmiedel D, Tai J, Yamin R, Berhani O, Bauman Y, Mandelboim O. The RNA binding protein IMP3 facilitates tumor immune escape by downregulating the stress-induced ligands ULPB2 and MICB. Elife (2016) 5:e13426. doi:10.7554/ eLife.13426

38. Stern-Ginossar N, Gur C, Biton M, Horwitz E, Elboim M, Stanietsky N, et al. Human microRNAs regulate stress-induced immune responses mediated by the receptor NKG2D. Nat Immunol (2008) 9:1065-73. doi:10.1038/ni.1642

39. Tsukerman P, Stern-Ginossar N, Gur C, Glasner A, Nachmani D, Bauman Y, et al. miR-10b downregulates the stress-induced cell surface molecule MICB, a critical ligand for cancer cell recognition by natural killer cells. Cancer Res (2012) 72:5463-72. doi:10.1158/0008-5472.CAN-11-2671

40. Whitley RJ, Roizman B. Herpes simplex virus infections. Lancet (2001) 357:1513-8. doi:10.1016/S0140-6736(00)04638-9

41. Siegel MA. Diagnosis and management of recurrent herpes simplex infections. J Am Dent Assoc (2002) 133:1245-9. doi:10.14219/jada.archive.2002.0366

42. Schepis D, D’Amato M, Studahl M, Bergstrom T, Karre K, Berg L. Herpes simplex virus infection downmodulates NKG2D ligand expression. Scand J Immunol (2009) 69:429-36. doi:10.1111/j.1365-3083.2009.02241.x

43. Campbell TM, McSharry BP, Steain M, Slobedman B, Abendroth A. Varicellazoster virus and herpes simplex virus 1 differentially modulate NKG2D ligand expression during productive infection. J Virol (2015) 89:7932-43. doi:10.1128/JVI.00292-15

44. Enk J, Levi A, Weisblum Y, Yamin R, Charpak-Amikam Y, Wolf DG, et al. HSV1 microRNA modulation of GPI anchoring and downstream immune evasion. Cell Rep (2016) 17:949-56. doi:10.1016/j.celrep.2016.09.077

45. Ohishi K, Inoue N, Kinoshita T. PIG-S and PIG-T, essential for GPI anchor attachment to proteins, form a complex with GAA1 and GPI8. EMBO J (2001) 20:4088-98. doi:10.1093/emboj/20.15.4088

46. Kinoshita T, Fujita M, Maeda Y. Biosynthesis, remodelling and functions of mammalian GPI-anchored proteins: recent progress. J Biochem (2008) 144:287-94. doi:10.1093/jb/mvn090

47. Gilden D, Cohrs RJ, Mahalingam R, Nagel MA. Varicella zoster virus vasculopathies: diverse clinical manifestations, laboratory features, pathogenesis, and treatment. Lancet Neurol (2009) 8:731-40. doi:10.1016/ S1474-4422(09)70134-6

48. Mueller NH, Gilden DH, Cohrs RJ, Mahalingam R, Nagel MA. Varicella zoster virus infection: clinical features, molecular pathogenesis of disease, and latency. Neurol Clin (2008) 26:675-697, viii. doi:10.1016/j.ncl.2008.03.011

49. Straus SE, Cohen JI, Tosato G, Meier J. NIH conference. Epstein-Barr virus infections: biology, pathogenesis, and management. Ann Intern Med (1993) 118:45-58. doi:10.7326/0003-4819-118-1-199301010-00009

50. Kawa K. Epstein-Barr virus-associated diseases in humans. Int J Hematol (2000) 71:108-17.
51. Tao Q, Chan AT. Nasopharyngeal carcinoma: molecular pathogenesis and therapeutic developments. Expert Rev Mol Med (2007) 9:1-24. doi:10.1017/ S1462399407000312

52. Pappworth IY, Wang EC, Rowe M. The switch from latent to productive infection in Epstein-Barr virus-infected B cells is associated with sensitization to NK cell killing. J Virol (2007) 81:474-82. doi:10.1128/JVI.01777-06

53. Nachmani D, Stern-Ginossar N, Sarid R, Mandelboim O. Diverse herpesvirus microRNAs target the stress-induced immune ligand MICB to escape recognition by natural killer cells. Cell Host Microbe (2009) 5:376-85. doi:10.1016/ j.chom.2009.03.003

54. Song H, Park H, Kim J, Park G, Kim YS, Kim SM, et al. IDO metabolite produced by EBV-transformed B cells inhibits surface expression of NKG2D in NK cells via the c-Jun $\mathrm{N}$-terminal kinase (JNK) pathway. Immunol Lett (2011) 136:187-93. doi:10.1016/j.imlet.2011.01.009

55. Griffiths P, Baraniak I, Reeves M. The pathogenesis of human cytomegalovirus. J Pathol (2015) 235:288-97. doi:10.1002/path.4437

56. Stern-Ginossar N, Elefant N, Zimmermann A, Wolf DG, Saleh N, Biton M, et al. Host immune system gene targeting by a viral miRNA. Science (2007) 317:376-81. doi:10.1126/science.1140956

57. Kubin M, Cassiano L, Chalupny J, Chin W, Cosman D, Fanslow W, et al. ULBP1, 2, 3: novel MHC class I-related molecules that bind to human cytomegalovirus glycoprotein UL16, activate NK cells. Eur J Immunol (2001) 31:1428-37. doi:10.1002/1521-4141(200105)31:5<1428:AID-IMMU1428>3.0.CO;2-4

58. Rolle A, Mousavi-Jazi M, Eriksson M, Odeberg J, Soderberg-Naucler C, Cosman D, et al. Effects of human cytomegalovirus infection on ligands for the activating NKG2D receptor of NK cells: up-regulation of UL16-binding protein (ULBP) 1 and ULBP2 is counteracted by the viral UL16 protein. J Immunol (2003) 171:902-8. doi:10.4049/jimmunol.171.2.902

59. Dunn C, Chalupny NJ, Sutherland CL, Dosch S, Sivakumar PV, Johnson DC, et al. Human cytomegalovirus glycoprotein UL16 causes intracellular sequestration of NKG2D ligands, protecting against natural killer cell cytotoxicity. J Exp Med (2003) 197:1427-39. doi:10.1084/jem.20022059

60. Wu J, Chalupny NJ, Manley TJ, Riddell SR, Cosman D, Spies T. Intracellular retention of the MHC class I-related chain B ligand of NKG2D by the human cytomegalovirus UL16 glycoprotein. J Immunol (2003) 170:4196-200. doi:10.4049/jimmunol.170.8.4196

61. Eagle RA, Traherne JA, Hair JR, Jafferji I, Trowsdale J. ULBP6/RAET1L is an additional human NKG2D ligand. Eur J Immunol (2009) 39:3207-16. doi:10.1002/eji.200939502

62. Ashiru O, Bennett NJ, Boyle LH, Thomas M, Trowsdale J, Wills MR. NKG2D ligand MICA is retained in the cis-Golgi apparatus by human cytomegalovirus protein UL142. J Virol (2009) 83:12345-54. doi:10.1128/JVI.01175-09

63. Bennett NJ, Ashiru O, Morgan FJ, Pang Y, Okecha G, Eagle RA, et al. Intracellular sequestration of the NKG2D ligand ULBP3 by human cytomegalovirus. J Immunol (2010) 185:1093-102. doi:10.4049/jimmunol.1000789

64. Fielding CA, Aicheler R, Stanton RJ, Wang EC, Han S, Seirafian S, et al. Two novel human cytomegalovirus NK cell evasion functions target MICA for lysosomal degradation. PLoS Pathog (2014) 10:e1004058. doi:10.1371/journal. ppat.1004058

65. Zhang Y, Lazaro AM, Lavingia B, Stastny P. Typing for all known MICA alleles by group-specific PCR and SSOP. Hum Immunol (2001) 62:620-31. doi:10.1016/S0198-8859(01)00241-5

66. Petersdorf EW, Shuler KB, Longton GM, Spies T, Hansen JA. Population study of allelic diversity in the human MHC class I-related MIC-A gene. Immunogenetics (1999) 49:605-12. doi:10.1007/s002510050655

67. Vales-Gomez M. The impact of glycosyl-phosphatidyl-inositol anchored MICA alleles on novel NKG2D-based therapies. Front Immunol (2015) 6:193. doi:10.3389/fimmu.2015.00193

68. Seidel E, Le VT, Bar-On Y, Tsukerman P, Enk J, Yamin R, et al. Dynamic coevolution of host and pathogen: HCMV downregulates the prevalent allele MICA *008 to escape elimination by NK cells. Cell Rep (2015) 10:968-82. doi:10.1016/j.celrep.2015.01.029

69. Kondo K, Yamanishi K. HHV-6A, 6B, and 7: molecular basis of latency and reactivation. In: Arvin A, Campadelli-Fiume G, Mocarski E, Moore PS, Roizman B, Whitley R, et al., editors. Human Herpesviruses: Biology, Therapy, and Immunoprophylaxis. Cambridge: Cambridge University Press (2007).

70. Ongradi J, Ablashi DV, Yoshikawa T, Stercz B, Ogata M. Roseolovirusassociated encephalitis in immunocompetent and immunocompromised individuals. J Neurovirol (2017) 23(1):1-19. doi:10.1007/s13365-016-0473-0 
71. Schmiedel D, Tai J, Levi-Schaffer F, Dovrat S, Mandelboim O. Human herpesvirus $6 \mathrm{~B}$ downregulates expression of activating ligands during lytic infection to escape elimination by natural killer cells. J Virol (2016) 90:9608-17. doi:10.1128/JVI.01164-16

72. Schneider CL, Hudson AW. The human herpesvirus-7 (HHV-7) U21 immunoevasin subverts NK-mediated cytoxicity through modulation of MICA and MICB. PLoS Pathog (2011) 7:e1002362. doi:10.1371/journal.ppat.1002362

73. Viejo-Borbolla A, Schulz TF. Kaposi's sarcoma-associated herpesvirus (KSHV/HHV8): key aspects of epidemiology and pathogenesis. AIDS Rev (2003) 5:222-9.

74. Cesarman E, Chang Y, Moore PS, Said JW, Knowles DM. Kaposi's sarcoma-associated herpesvirus-like DNA sequences in AIDS-related bodycavity-based lymphomas. N Engl J Med (1995) 332:1186-91. doi:10.1056/ NEJM199505043321802

75. Thomas M, Boname JM, Field S, Nejentsev S, Salio M, Cerundolo V, et al. Down-regulation of NKG2D and NKp80 ligands by Kaposi's sarcoma-associated herpesvirus K5 protects against NK cell cytotoxicity. Proc Natl Acad Sci U S A (2008) 105:1656-61. doi:10.1073/pnas.0707883105

76. Stern-Ginossar N, Weisburd B, Michalski A, Le VT, Hein MY, Huang SX, et al. Decoding human cytomegalovirus. Science (2012) 338:1088-93. doi:10.1126/ science. 1227919

77. Arias C, Weisburd B, Stern-Ginossar N, Mercier A, Madrid AS, Bellare P, et al. KSHV 2.0: a comprehensive annotation of the Kaposi's sarcoma-associated herpesvirus genome using next-generation sequencing reveals novel genomic and functional features. PLoS Pathog (2014) 10:e1003847. doi:10.1371/ journal.ppat.1003847

78. Tycowski KT, Guo YE, Lee N, Moss WN, Vallery TK, Xie M, et al. Viral noncoding RNAs: more surprises. Genes Dev (2015) 29:567-84. doi:10.1101/ gad.259077.115

79. Zhang Q, Jeang KT. Long non-coding RNAs (lncRNAs) and viral infections. Biomed Pharmacother (2013) 3:34-42. doi:10.1016/j.biomed.2013.01.001

80. Samarakoon A, Chu H, Malarkannan S. Murine NKG2D ligands: "double, double toil and trouble". Mol Immunol (2009) 46:1011-9. doi:10.1016/j. molimm.2008.09.035

81. Meyer A, Carapito R, Ott L, Radosavljevic M, Georgel P, Adams EJ, et al. High diversity of MIC genes in non-human primates. Immunogenetics (2014) 66:581-7. doi:10.1007/s00251-014-0791-4

82. Anzai T, Shiina T, Kimura N, Yanagiya K, Kohara S, Shigenari A, et al. Comparative sequencing of human and chimpanzee MHC class I regions unveils insertions/deletions as the major path to genomic divergence. Proc Natl Acad Sci U S A (2003) 100:7708-13. doi:10.1073/pnas.1230533100

83. de Groot NG, Garcia CA, Verschoor EJ, Doxiadis GG, Marsh SG, Otting N, et al. Reduced MIC gene repertoire variation in West African chimpanzees as compared to humans. Mol Biol Evol (2005) 22:1375-85. doi:10.1093/molbev/ msil27

84. Spreu J, Stehle T, Steinle A. Human cytomegalovirus-encoded UL16 discriminates MIC molecules by their alpha2 domains. J Immunol (2006) 177:3143-9. doi:10.4049/jimmunol.177.5.3143

85. Klumkrathok K, Jumnainsong A, Leelayuwat C. Allelic MHC class I chain related $\mathrm{B}$ (MICB) molecules affect the binding to the human cytomegalovirus (HCMV) unique long 16 (UL16) protein: implications for immune surveillance. J Microbiol (2013) 51:241-6. doi:10.1007/s12275-013-2514-1

86. Renzette N, Pokalyuk C, Gibson L, Bhattacharjee B, Schleiss MR, Hamprecht $\mathrm{K}$, et al. Limits and patterns of cytomegalovirus genomic diversity in humans. Proc Natl Acad Sci U S A (2015) 112:E4120-8. doi:10.1073/pnas. 1501880112

87. Sijmons S, Thys K, Mbong Ngwese M, Van Damme E, Dvorak J, Van Loock $\mathrm{M}$, et al. High-throughput analysis of human cytomegalovirus genome diversity highlights the widespread occurrence of gene-disrupting mutations and pervasive recombination. J Virol (2015) 89:7673-95. doi:10.1128/JVI. 00578-15

88. Komatsu-Wakui M, Tokunaga K, Ishikawa Y, Kashiwase K, Moriyama S, Tsuchiya N, et al. MIC-A polymorphism in Japanese and a MIC-A-MIC-B null haplotype. Immunogenetics (1999) 49:620-8. doi:10.1007/s002510050658

89. Ota M, Bahram S, Katsuyama Y, Saito S, Nose Y, Sada M, et al. On the MICA deleted-MICB null, HLA-B ${ }^{\star} 4801$ haplotype. Tissue Antigens (2000) 56:268-71. doi:10.1034/j.1399-0039.2000.560309.x

90. Komatsu-Wakui M, Tokunaga K, Ishikawa Y, Leelayuwat C, Kashiwase K, Tanaka H, et al. Wide distribution of the MICA-MICB null haplotype in East Asians. Tissue Antigens (2001) 57:1-8. doi:10.1034/j.1399-0039.2001. 057001001.x

91. Aida K, Russomando G, Kikuchi M, Candia N, Franco L, Almiron M, et al. High frequency of MIC null haplotype (HLA-B48-MICA-del-MICB ${ }^{\star} 0107 \mathrm{~N}$ ) in the Angaite Amerindian community in Paraguay. Immunogenetics (2002) 54:439-41. doi:10.1007/s00251-002-0485-1

Conflict of Interest Statement: The authors declare that the research was conducted in the absence of any commercial or financial relationships that could be construed as a potential conflict of interest.

Copyright (c) 2017 Schmiedel and Mandelboim. This is an open-access article distributed under the terms of the Creative Commons Attribution License (CC BY). The use, distribution or reproduction in other forums is permitted, provided the original author(s) or licensor are credited and that the original publication in this journal is cited, in accordance with accepted academic practice. No use, distribution or reproduction is permitted which does not comply with these terms. 